\title{
Watch party lectures: synchronous delivery of asynchronous material
}

\section{Carolina E. Kuepper-Tetzel}

University of Glasgow

\section{Emily Nordmann}

University of Glasgow

Keywords: instruction; lectures; synchronous and asynchronous learning; student engagement; Covid-19

\section{The challenge}

When the Covid-19 pandemic hit in early 2020, the majority of university activities on campus were suspended across the world, and teaching pivoted online (Nordmann et al., 2020). The challenge was to provide students who were enrolled and expecting a face-to-face, oncampus learning experience with a similar university experience that would encourage them to engage with learning and to develop a sense of belonging (Peacock et al., 2020). As year leads for first- and second-year Psychology at our university, our cohorts were particularly large with approximately 600 first-year students and 250 second-year students. Each week students attend three to five lectures and one practical lab session, and previously all teaching was delivered in person on campus.

In the process of planning our move online, we realised the need to develop an approach that offered both asynchronous and synchronous elements. Synchronous sessions are vital, not only for community building, but there is also a positive association between scheduled teaching of lectures and practicals and academic achievement (Torenbeek et al., 2012). However, with students studying from home in different countries, under a variety of circumstances, and with differential access to internet, study space and technology, it was important to offer all essential teaching material asynchronously too (Nordmann et al., 2020). 
In the initial period of emergency remote teaching directly following the first lockdown, we kept in touch with students through online remote social activities such as meeting online for a watch party of psychology-related movies and used the integrated chat box function to write comments or thoughts. This was when the concept of 'watch party lectures' was born.

\section{The response}

Watch party lectures combine asynchronous and synchronous teaching approaches. Lecturers record short videos of directly instructed content; for one-hour lectures, lecturers aim to record 2-3 short videos for a maximum of 40-45 minutes. These pre-recorded videos are uploaded onto the virtual learning environment (VLE). However, the crucial element of watch party lectures is the scheduled, synchronous time during which these pre-recordings are watched together via screen sharing. Watch parties purposely differ from a flipped classroom approach in which students are required to complete the pre-recordings in their own time before coming to class. While, in general, the flipped classroom approach has shown positive effects on student performance across educational sectors and disciplines (Strelan et al., 2020), students, particularly younger cohorts, may become overwhelmed by the added requirement of independent learning and, consequently, not complete the learning activities prior to class (Tomas et al., 2019). This may be more pronounced now as students report additional strains on mental health and wellbeing during the pandemic (e.g., Chirikov et al., 2020; Mechili et al., 2020; Wang et al., 2020). Thus, watch party lectures offer a scheduled time during which the core teaching content is delivered.

Perhaps more importantly, watch party sessions allowed for meaningful interactions between lecturers and students while watching the videos. Students would post questions or comments in the chat box, and the lecturer could address them immediately, for example, by providing links to additional resources. We observed more engagement during watch party lectures from a more diverse body of students than we have experienced in face-to-face lectures, which reflects students' preference for using the chat box during instruction (see $\mathrm{Vu}$ and Fadde, 2013). Collaborative co-creation of knowledge that combines social and cognitive 
processes aligns well with the theoretical framework of Community of Inquiry (Garrison et al., 2001; Cleveland-Innes et al., 2019); and is an essential aspect of watch party lectures. Discussion took place not only between lecturers and students, but also between peers who would frequently answer questions or provide follow-up opinions and thoughts to points raised in the chat. Besides the ongoing discussions, lecturers enriched the watch party sessions with short quiz activities, either to review previously taught material or to prompt upcoming content. Quizzing during lectures not only provides students with a short break from watching the videos, but is also a beneficial strategy to increase retention and transfer of knowledge (Thomas et al., 2020).

Although multiple platforms would be capable of presenting watch parties, we used Zoom (Zoom Video Communications Inc, 2016). In addition to being adopted as a core technology by our institution, Zoom had no known restrictions in terms of international access and was also available for students on mobile devices, and we were not made aware of any cases in which students who wished to engage with the sessions were not able to do so. Recordings of the watch party sessions including the chat conversations were also made available to students for asynchronous engagement, although the community and active learning benefits of the sessions would have been limited.

The feedback from students on the watch party lectures has been overwhelmingly positive, for example:

I like that all lectures are watch party style, it makes it feel more interactive and 'normal'. None of my other subjects have done this so every week I look forward to my psychology lectures. (Anonymous, 2020a)

Online live lecture watch parties are amazing because it feels a lot more engaging than just having to watch the already recorded lecture alone. (Anonymous, 2020b)

In student evaluations, our approach was praised as an effective way to engage with the material, ask questions during the session, and catch-up afterwards. Students appreciated 
the different activities during the watch party sessions, citing that these kept them focused and encouraged further elaboration on the topic. As expected, students highlighted the chat box conversations as a positive feature of watch party lectures. Student feedback was so positive that the format was adopted by other lecturers and departments at both our own and other institutions.

\section{Recommendations}

Lecturers interested in implementing this approach may experience an initial hesitation about watching themselves during the watch party session, but from our own experiences and from speaking to our colleagues, this was not perceived as an issue, or was one that quickly became normal. Lecturers enjoyed the interactions in the chat box, which allowed them time to construct more elaborate answers to student questions. When moving back to face-to-face lectures, we recommend integrating text-based chats during lectures. Lecturers could encourage students to post comments and questions during the lecture using existing tools (e.g., Teams, forums on the VLE) and then take brief Q\&A breaks during the lecture. After the lecture, the lecturer could reply to questions that require more elaborate answers or additional resources.

In conclusion, watch party lectures demonstrate the benefits of strategically combining asynchronous and synchronous approaches. When considering what the new normal of lectures will look like, it is crucial to consider their social and community aspects (Nordmann et al., 2021), and we strongly recommend integrating both asynchronous and synchronous elements regardless of the modality or format of teaching delivery.

\section{References}

Chirikov, I., Soria, K.M., Horgos, B, and Jones-White, D. (2020) 'Undergraduate and graduate students' mental health during the COVID-19 pandemic', UC Berkeley: Center for 
Studies in Higher Education, viewed 3 June 2021. Available at: https://escholarship.org/uc/item/80k5d5hw (Accessed: 30 June 2021).

Cleveland-Innes, M., Gauvreau, S., Richardson, G., Mishra, S. and Ostashewski, N. (2019) 'Technology-enabled learning and the benefits and challenges of using the Community of Inquiry theoretical framework', International Journal of E-Learning \& Distance Education, 34(1), pp.1-18.

Garrison, D.R., Anderson, T. and Archer, W. (2001) 'Critical thinking, cognitive presence, and computer conferencing in distance education', American Journal of Distance Education,15(1), pp. 7-23. Available at: https://doi.org/10.1080/08923640109527071 (Accessed: 30 June 2021).

Mechili, E.A., Saliaj, A., Kamberi, F., Girvalaki, C., Peto, E., Patelarou, A.E., Bucaj, J. and Patelarou, E. (2020) 'Is the mental health of young students and their family members affected during the quarantine period? Evidence from the COVID-19 pandemic in Albania', Journal of Psychiatric and Mental Health Nursing, 28(3), pp.317-325. Available at: https://doi.org/10.1111/jpm.12672 (Accessed: 5 July 2021).

Nordmann E., Horlin, C., Hutchison, J., Murray, J.A., Robson, L., Seery, M.K. and MacKay, J.R.D. (2020) 'Ten simple rules for supporting a temporary online pivot in higher education', PLoS Computational Biology, 16(10), pp.e1008242. Available at: https://doi.org/10.1371/journal.pcbi.1008242 (Accessed: 5 July 2021).

Nordmann, E., Hutchison, J. and MacKay, J.R.D. (2021) 'Lecture rapture: the place and case for lectures in the new normal', EdArXiv. Available at: https://doi.org/10.35542/osf.io/h8zt6 (Accessed: 5 July 2021).

Peacock, S., Cowan, J., Irvine, L. and Williams, J. (2020) 'An exploration into the importance of a sense of belonging for online learners', The International Review of Research in 
Open and Distributed Learning, 21(2), pp. 18-35. Available at:

https://doi.org/10.19173/irrodl.v20i5.4539 (Accessed: 5 July 2021).

Torenbeek, M., Jansen, E. and Suhre, C. (2013) 'Predicting undergraduates' academic achievement: the role of the curriculum, time investment and self-regulated learning', Studies in Higher Education, 38(9), pp. 1393-1406. Available at: https://doi.org/10.1080/03075079.2011.640996 (Accessed: 5 July 2021).

Strelan, P., Osborn, A. and Palmer, E. (2020) 'The flipped classroom: a meta-analysis of effects on student performance across disciplines and education levels', Educational Research Review, 30, pp. 100314. Available at: https://doi.org/10.1016/j.edurev.2020.100314 (Accessed: 5 July 2021).

Thomas, A.K., Smith, A.M., Kamal, K. and Gordon, L.T. (2020) 'Should you use frequent quizzing in your college course? Giving up 20 minutes of lecture time may pay off', Journal of Applied Research in Memory and Cognition, 9(1), pp. 83-95. Available at: https://doi.org/10.1016/j.jarmac.2019.12.005 (Accessed: 5 July 2021).

Tomas, L., Doyle, T. and Skamp, K. (2019) 'Are first year students ready for a flipped classroom? A case for a flipped learning continuum', International Journal of Educational Technology in Higher Education, 16(1), pp.1-22. Available at: https://doi.org/10.1186/s41239-019-0135-4 (Accessed: 5 July 2021).

Wang, X., Hegde, S., Son, C., Keller, B., Smith, A. and Sasangohar, F. (2020) 'Investigating mental health of US college students during the COVID-19 pandemic: cross-sectional survey study', Journal of Medical Internet Research, 22(9), pp. e22817. Available at: https://doi.org/10.2196/22817 (Accessed: 5 July 2021).

Vu, P. and Fadde, P.J. (2013) 'When to talk, when to chat: student interactions in live virtual classrooms', Journal of Interactive Online Learning, 12(2), pp.41-52. Available at: http://www.ncolr.org/jiol/issues/pdf/12.2.1.pdf (Accessed: 5 July 2021). 
Zoom Video Communications Inc. (2016) Security guide. Available at:

https://d24cgw3uvb9a9h.cloudfront.net/static/81625/doc/Zoom-Security-WhitePaper.pdf (Accessed: 30 June 2021).

\section{Author details}

Carolina E. Kuepper-Tetzel is a Senior Lecturer in Psychology at the University of Glasgow and a Senior Fellow of the HEA. She is an expert in applying findings from cognitive science to education and an enthusiastic science communicator. She is a member of The Learning Scientists and the founder of the Teaching Innovation \& Learning Enhancement (TILE) network. You can follow her work on Twitter: @pimpmymemory.

Emily Nordmann is a Senior Lecturer in Psychology at the University of Glasgow and was awarded the British Psychological Society HE Psychology Teacher of the Year in 2020. She is an expert in lecture capture and a strong proponent of open educational resources and the teaching of reproducible research methods. You can follow her work on Twitter: @emilynordmann. 